\title{
Urban Flood Prevention and Early Warning System in Jinan City
}

\author{
Shiyuan Feng, Qingguo Li ${ }^{*}$ \\ School of Water Conservancy and Environment, University of Jinan, Shandong Province, 250022, China
}

\begin{abstract}
The system construction of urban flood control and disaster reduction in China is facing pressure and challenge from new urban water disaster. Under the circumstances that it is difficult to build high standards of flood protection engineering measures in urban areas, it is particularly important to carry out urban flood early warning. In Jinan City, a representative inland area, based on the index system of early warning of flood in Jinan urban area, the method of fuzzy comprehensive evaluation was adopted to evaluate the level of early warning. Based on the cumulative rainfall of 3 hours, the CAflood simulation results based on cellular automaton model of urban flooding were used as evaluation indexes to realize the accuracy and integration of urban flood control early warning.
\end{abstract}

\section{Introduction}

With the development of urbanization, the system of urban flood disaster is changing constantly. For example, the change of urban underlying surface causes the change of urban runoff [1]; the continuous expansion of urban land use has led to increased pressure on the drainage system [2]; the continuous increase of population and property in the built-up area has raised the vulnerability facing floods and other disasters. The "7.18" incident in Jinan in 2007 and the "7.21" incident in Beijing in 2012 have caused serious losses to people's lives and property [3].

Therefore, it is a commonly used and effective method to carry out flood control and early warning for preventing and controlling floods in urban areas. When more serious floods occur, emergency measures for prevention and control of floods are taken. In order to seek a positive and effective coping strategy, many scholars and management agencies have done a great deal of research and practice in the field of flood control and early warning [4]. There are a lot of experience and methods to be learnt from in flood control and early warning mode, early warning index system and the classification of early warning. Based on the analysis of the representative flood control and early warning technology at home and abroad, comparing and drawing on experiences from the early-warning model which has good effect and universality, this paper studies the construction of urban flood control early warning system in urban area of Jinan City.

\section{Index System and Comprehensive Evaluation Model of Flood Warning in Jinan City}

Early warning is given based on established or promulgated early warning modes. This work generally evaluates the warning level comprehensively according to the early warning indicators. The index system of early warning of flood in urban area of Jinan is the basis for flood control and early warning. Only an integrated early-warning index system which can meet the actual situation of Jinan and reflect the urban police intelligence under different conditions can be established to make accurate early warning based on real-time early warning.

First of all, we need to determine the classification of early warning mode, and then grade the various early warning indicators proposed above. According to the multistage response mechanism of national public emergency, this study divided each evaluation index into 5 levels on the basis of identifying early warning indicators, corresponding to 5 levels of response measures respectively.

\subsection{Warning indicator system of Jinan urban flood}

Evaluation level.

(1) Grade I: severely affected, heavy losses from flooding or serious traffic congestion or casualties.

(2) Grade II: moderately affected, serious flooding loss or serious impact but no casualties.

(3) Grade III: mildly affected, inconvenient for residents to travel, poor traffic, and slight loss in some areas.

(4) Grade IV: safety, there is water accumulation in the pavement, but the depth is shallower, so no disaster loss has occurred.

(5) Grade V: safe, no alarm or alarm clear.

Indicator system.

\footnotetext{
* Corresponding author: Qingguo Li@ffengshiyuan@126.com
} 
Determine the threshold for dividing each indicator into four levels. The indicators and indicator value standards in the city-wide unified are as follows.

(1) $3 \mathrm{~h}$ (3 hours) cumulative rainfall (P3h)

The main driving force of urban floods is mostly heavy rainfall. Although storm surge in some coastal areas in China may also cause urban floods, it is only a case and the storm surge index is not easy to be quantified. Therefore, it is usually indicated by rainfall over a certain period of time to indicate urban floods early warning of the driving force. According to our experience in urban flood protection, generally when $3 \mathrm{~h}$ continuous rainfall reaches a certain value, it will induce urban floods, so $3 \mathrm{~h}$ cumulative rainfall as an indicator of urban flood warning can be used in Jinan. Of course, it is subjective to adopt the early warning index of accumulative rainfall for 3 hours. According to the actual situation in Jinan, $6 \mathrm{~h}$ and $12 \mathrm{~h}$ cumulative rainfall can be used in some regions for higher warning level.

The $3 \mathrm{~h}$ accumulated rainfall, $\mathrm{P} 3 \mathrm{~h}$, is divided into 5 levels, with reference to the current method for classifying storm rains in the domestic meteorological department. The $\mathrm{P} 3 \mathrm{~h}$ is divided according to the following criteria:

P3h $<30 \mathrm{~mm}$, level $\vee$;

$30 \mathrm{~mm} \leqslant \mathrm{P} 3 \mathrm{~h}<50 \mathrm{~mm}$, level IV;

$50 \mathrm{~mm} \leqslant \mathrm{P} 3 \mathrm{~h}<100 \mathrm{~mm}$, level III;

$100 \mathrm{~mm} \leqslant \mathrm{P} 3 \mathrm{~h}<150 \mathrm{~mm}$, level $\|$;

$\mathrm{P} 3 \mathrm{~h} \geqslant 150 \mathrm{~mm}$, level $\mathrm{I}$.

(2) Submerged depth (Hn)

Submerged depth and range are important indicators for describing the status of floods and the submerged depth of water is the most important basis for determining whether floods occur. Under the condition that the underlying surface is invariant, the submerged depth is completely related to the submerged area. Therefore, according to the principle of appropriate number of indicators selected by evaluation index, only the depth of flood inundation is taken as the early warning indicator to describe flood disaster status.

In flood control and early warning, submerged depth, $\mathrm{Hn}$, is a key indicator, which is closely related to the disaster area and disaster losses. The flowing grading standards are proposed:

$\mathrm{Hn}<20 \mathrm{~cm}$, level $\vee$;

$20 \mathrm{~cm} \leqslant \mathrm{Hn}<50 \mathrm{~cm}$, level IV;

$50 \mathrm{~cm} \leqslant \mathrm{Hn}<100 \mathrm{~cm}$, level III;

$100 \mathrm{~cm} \leqslant \mathrm{Hn}<200 \mathrm{~cm}$, level II;

$\mathrm{Hn} \geqslant 200 \mathrm{~cm}$, level । .

(3) Flow rate index $(\mathrm{Vn})$

Flood velocity is also a major indicator that describes the status of floods. It plays a certain role in promoting floods and is closely related to the extent of disaster and the loss of floods. Therefore, in flood control and early warning, flow rate $(\mathrm{Vn})$ of the key sections (road nodes, overpasses, etc.) also is an important indicator of early warning. Referencing to the division of disaster bearing capacity of flow indicators and urban traffic, life and construction of esidents in Saint Martin Island flood disaster management research, the following grading standards are proposed:

$\mathrm{Vn}<0.5 \mathrm{~m} / \mathrm{s}$, level $\vee$;

$0.5 \mathrm{~m} / \mathrm{s} \leqslant \mathrm{Vn}<2.0 \mathrm{~m} / \mathrm{s}$, level IV;

$2.0 \mathrm{~m} / \mathrm{s} \leqslant \mathrm{Vn}<3.0 \mathrm{~m} / \mathrm{s}$, level III;

$3.0 \mathrm{~m} / \mathrm{s} \leqslant \mathrm{Vn}<4.0 \mathrm{~m} / \mathrm{s}$, level $\|$;

$\mathrm{Vn} \geqslant 4.0 \mathrm{~m} / \mathrm{s}$, level ।.

(4) Index of Flood Control Integrated Management Efficiency $(\lambda)$

Efficiency coefficient of integrated flood control is not easy to be quantified, because there are no feasible methods to determine it with objectivity. In specific works, we can combine the practical experience of grassroots staff to conduct a comprehensive evaluation. According to whether it has built and come into use the decision support system of three defenses and it has been tested by practice, flood control contingency plans for the operational situation, the construction of urban drainage network system, the effectiveness of urban hedge, flood management efficiency coefficient $\lambda$ is divided into the following levels.

$\lambda \geqslant 0.9$, level $\vee$, Basically no effect;

$0.7 \leqslant \lambda<0.9$, level IV, Slight affected;

$0.5 \leqslant \lambda<0.7$, level III, Mild effect;

$0.3 \leqslant \lambda<0.5$, level II , Moderate effect;

$\lambda<0.3$, level । , Severe effect.

In the actual early warning work, all or part of the above indicators can be selected for early warning evaluation based on the obtained data and information, meteorological hydrology and socio-economic characteristics of different sub-regions. The standard division for flood early warning in urban area of Jinan City is detailed in Table 1.

Table 1. Warning early warning criteria division of Jinan urban area

\begin{tabular}{|c|c|}
\hline & $\begin{array}{c}\text { threshold indicator of early } \\
\text { warning }\end{array}$ \\
& $\mathrm{P} 3 \mathrm{~h} \geqslant 150 \mathrm{~mm} ;$ \\
$\mathrm{Hn} \geqslant 200 \mathrm{~cm} ;$ \\
$\mathrm{Vn} \geqslant 4.0 \mathrm{~m} / \mathrm{s}$ \\
$\lambda<0.3$.
\end{tabular}




\begin{tabular}{|c|c|}
\hline & $\mathrm{P} 3 \mathrm{~h}<30 \mathrm{~mm} ;$ \\
$\mathrm{Hn}<20 \mathrm{~cm}$ \\
$\mathrm{Vn}<0.5 \mathrm{~m} / \mathrm{s}$ \\
$\lambda \geqslant 0.9$.
\end{tabular}

\subsection{Fuzzy comprehensive evaluation method for early warning level}

Start-up of flood warning level in a city can not be activated only according to a certain indicator that reaches a certain warning level. We need to make a comprehensive analysis of all the indicators in order to give a warning level that truly reflects floods and floods in urban areas and provide more precise warning information for flood control departments so as to ensure the correct and efficient operation of urban flood control. Therefore, it is one of the key technologies for early warning of urban floods to establish a comprehensive evaluation model and comprehensively analyze each independent early warning index so as to give the warning level. In this paper, the method of fuzzy evaluation method is used to establish the fuzzy comprehensive evaluation model method of Jinan with the combination of subjectivity and objectivity.

The evaluation results are divided into a certain level, taking this study as an example, Grade I、Grade II、

Grade III、Grade IV、Grade V. The formulas are as follows. There are $\mathrm{n}$ precautionary zones, $\mathrm{m}$ precautionary indicators in the zone of the measured value $\mathrm{x}$ and then the evaluation indicator matrix can be obtained.

$$
X=\left[\begin{array}{cccc}
x_{11} & x_{12} & \Lambda & x_{1 n} \\
x_{21} & x_{22} & \Lambda & x_{2 n} \\
\Lambda & \Lambda & \Lambda & \Lambda \\
x_{m 1} & x_{m 2} & \Lambda & x_{m n}
\end{array}\right]=\left(x_{i j}\right)
$$

According to the index number, $m$, the standard value of the evaluation index is $\mathrm{y} . \mathrm{m}$ indicators c-level standard value matrix is as follows.

$$
Y=\left[\begin{array}{cccc}
y_{11} & y_{12} & \Lambda & y_{1 c} \\
y_{21} & y_{22} & \Lambda & y_{2 c} \\
\Lambda & \Lambda & \Lambda & \Lambda \\
y_{m 1} & y_{m 2} & \Lambda & y_{m c}
\end{array}\right]=\left(y_{i h}\right)
$$

Here , $i=1,2, l, m ; j=1,2, l, n ; h=1,2, l, c$, According to the above Jinan flood warning mode, the warning level is divided into 5 levels, so $c=5$.

Apply Formulas (3), (4):

$$
\begin{gathered}
r_{i j}=\frac{x_{i j}-y_{i c}}{y_{i 1}-y_{i c}} \\
s_{i h}=\frac{y_{i h}-y_{i c}}{y_{i 1}-y_{i c}}
\end{gathered}
$$

Normalize the matrix $\mathrm{X}$ and the matrix $\mathrm{Y}$ to obtain the corresponding normalized precalculation index normalization matrix and precautionary classification standard normalized matrix (5), (6).

$$
\begin{aligned}
R & =\left[\begin{array}{llll}
r_{11} & r_{12} & \Lambda & r_{1 n} \\
r_{21} & r_{22} & \Lambda & r_{2 n} \\
\Lambda & \Lambda & \Lambda & \Lambda \\
r_{m 1} & r_{m 2} & \Lambda & r_{m n}
\end{array}\right]=\left(r_{i j}\right) \\
S & =\left[\begin{array}{llll}
s_{11} & s_{12} & \Lambda & s_{1 c} \\
s_{21} & s_{22} & \Lambda & s_{2 c} \\
\Lambda & \Lambda & \Lambda & \Lambda \\
s_{m 1} & s_{m 2} & \Lambda & s_{m c}
\end{array}\right]=\left(s_{i h}\right)
\end{aligned}
$$

The weight of each of the early warning indicators is different, according to the previous method of determining the weight of indicators, here assume that the index weight vector is as fllows.

$$
\omega=\left(\omega_{1}, \omega_{2}, \Lambda \omega_{m}\right) \text { and meet } \sum_{i=1}^{m} \omega_{i}=1
$$

According to the theory of relative fuzzy comprehensive evaluation, this study gives the fuzzy comprehensive evaluation model of the warning level:

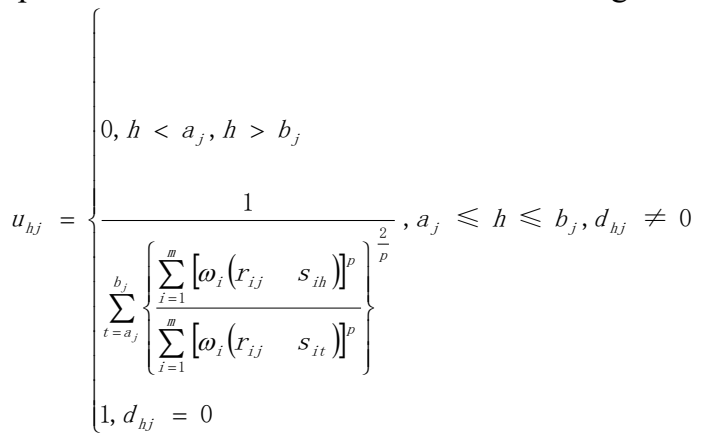

Here, the relative membership degree, uhj, that indicates that the alarm of the $j$-th pre-alarm zone of the system belongs to the relative membership degree of flood warning level h. $P$ is the distance coefficient, $p=1$ in this study, which means the generalized weighted distance.

Thus, according to uhj, the final warning level of partition $\mathrm{j}$ can be obtained.

$$
h_{j}=(1,2,3,4,5) \cdot\left(u_{1 j}, u_{2 j}, \cdots, u_{5 j}\right)^{T}
$$

Here, $h_{j}$ indicates which level $\mathrm{I} \sim \mathrm{V}$ partition $j$ belongs to, namely its integrated warning level.

\section{Simulation and Early Warning of Rain Flood in Jinan City}

On the basis of reasonable set of the early warning and starting criteria beforehand, according to the simulation scheme of standard design flood at all levels, the rainflood simulation model is used to simulate the design scheme, and the warning and response of each scheme 
design flood scenario are studied based on the calculation results. The validity and rationality of Jinan urban flood early warning indicator system and comprehensive grading evaluation method are tested and need to be demonstrated further. The simulation model of urban rainstorm uses Caflood[5,6], a two-dimensional flood simulation software of Water Center of Exeter University. By using the established flood simulation model, the four-color rainstorm warning corresponding flood simulation plan, the historical typical storm and the floodplain simulation plan corresponding to the municipal design rainstorms with different recurring periods were made. Flood simulation of the flood process is dynamic and continuous, and in order to show the most important feature of the entire submergence process, the representative moment is intercepted. The relevant warning level is shown in Figure 1.



Fig. 1. 3h-50mm Rainstorm warning simulation

From the simulation results, the urban area began to accumulate water two hours after the rainfall for 2 hours. The condition of water accumulation was not very serious. Most of the areas were level $V$-IV warnings and no level I warning areas. Urban water when the most serious 5 o'clock occurred. The key flood areas is in the central and northern regions, which also confirms the argument of " South floods North Waterlogging" after rainstorm in Jinan.

\section{Conclusion}

The application of urban desert simulation technology for flood early warning research can provide detailed flood risk information for urban flood control and disaster relief and provide accurate information for urban flood control organizations to carry out flood control and emergency management of zoning, time-sharing, classification and grading reliable flood warning information. It can be seen from the simulation results that the fuzzy comprehensive evaluation method has the ability to refine warning waterlogging, and the results of early warning are in accordance with the actual situation.

\section{References}

1. B Shi, D Wan, et al, Water Resources and Power, 06:57-60 (2014)

2. N Liu, X Bing, et al, Water Resources and Power, 06:48-52 (2016)

3. G Hou, ShanDong University, (2012)

4. $\mathrm{Y}$ Chen, $\mathrm{H}$ Zhang, $\mathrm{G}$ Du, CHINA FLOOD \& DROUGHT MANAGEMENT, 25;4:25-32 (2015)

5. M Guidolin, A S Chen, B Ghimire, et al. Environ. Modell. Softw. 84:378-394 (2016)

6. R J Austin, A S Chen, D A Savić, et al. J. Hydroinform. 16;6: 1359-1374 (2014). 